\title{
Research of reliability and efficiency of technological processes of mechanical assembly production on the basis of the common semi-Markov model
}

\author{
Yuri Rapatskiy ${ }^{1, ~}{ }^{*}$, Mikhail Zamorenov ${ }^{1}$, Vadim Kopp $^{1}$,Yuri Obzherin ${ }^{1}$,Vladimir Gusev ${ }^{2}$, \\ and Victoria Lipka ${ }^{3}$ \\ ${ }^{1}$ Sevastopol State University, 299053 Sevastopol, 33, University street, Russia \\ ${ }^{2}$ Donetsk National Technical University , 58, Artema street, Donetsk, Donetsk People's Republic \\ ${ }^{3}$ Philal FGBOU VO «State Maritime University named after Admiral F.F. Ushakov» in the city of \\ Sevastopol, 299001, Sevastopol, 7, Heroes of Sevastopol street, Russia
}

\begin{abstract}
In the article a common semi-Markov mathematical model is considered that allows one to investigate the productivity and reliability of various technological processes of mechanical assembly production. The proposed model allows to study, inter alia, technological processes of manufacturing parts with screw and assemblies of threaded connections. Mathematical apparatus of the research is the theory of semi-Markov processes with a common phase space, which operates with a common kind of random variables distribution functions. If the considering process in the system is a subsystem located on a higher level of hierarchy, the hierarchical model for compatibility with each other levels as output simulation parameters required distribution functions. In the proposed model, based on the decision of the Markov renewal equations depend not only on the torque characteristics, but also the distribution function of time per unit of output service according to different kinds of undervalued failures.
\end{abstract}

In engineering and other industries it is often necessary to analyze the relationship of life cycle phases (LC) of product, which is manifested in the form of technological heredity [1]. The purpose of the study is to build a common semi-Markov model that allows to investigate the productivity and reliability of various technological processes (TP) of the mechanical assembly production (MAP), including the manufacture of threaded parts and the automated assembly of threaded connections (TC), taking into account various types of failures.

Publications $[2,3,4,5,6,7]$ confirm the effectiveness of the application of semiMarkov mathematical models allowing to determine the productivity of serving devices (SD), for modeling and research of TP of MAP taking into account their reliability. As the $\mathrm{SD}$, we will consider various technological modules (TM), on the basis of which models the production system as a whole is modeled. The service cycle time of a unit of production

\footnotetext{
*Corresponding author: u.1.rapatskiy@mail.ru
} 
in a production system is the most informative characteristic of its productivity. In the simulation, it is necessary to take into account the stochastic nature of the service time, uptime and recovery TP $[2,3,4,5,6,7,8]$.

Threaded connections (TC) constitute up to $70 \%$ of the means of fixation of parts used in mechanical engineering products (MEP) $[9,10]$. The criterion of the quality of TC, affecting the reliability of MEP, is the non-opening of the joint during operation $[9,10]$. One of the most effective ways of obtaining TDs with external thread (ET) in mass production is thread-rolling on double-roller machines $[1,9,10,11,12]$. According to experiments and research, the greatest influence on the quality of the TD has TP threadrolling and genetic information conveyed to workpieces at a process for manufacturing stages inheritance $[1,9,10,11,12]$. As an example, consider the construction of the semiMarkov model TP thread-rolling. The reliability of the thread-rolling machine depends on a number of factors, the most important of which are the accuracy of the diameter and shape of the workpiece, the hardness and plasticity of the material, the correct installation of the workpiece on the machine and the degree of wear of thread rollers (TR), compliance with technological regimes $[9,13,14,15]$. Geometric and precision parameters of workpieces and TDs formed on technological transitions are random variables (RB), mathematical expectations, variances and distribution functions (DF) of which can be obtained by statistical processing and analysis of the results of production experiments. Experimental distributions of RV, for the convenience of research, using the apparatus of neural networks [16], can be replaced by a generalized Erlang law of the second and higher orders [17]. The experimental values of the expectation of uptime and recovery elements TP thread-rolling, for four of the most frequent failures are presented in the table. The elements of the TP will be considered as part of the process equipment and the RD values of parameters. Inadmissible values of the parameters of TD will be considered as TP failures.

Table 1. Experimental values of mathematical expectation uptime and recovery elements $\mathrm{TP}, \mathrm{h}$

\begin{tabular}{|l|c|c|c|c|}
\hline \multirow{2}{*}{$\begin{array}{l}\text { The mean values } \\
\text { of time } \\
\text { parameters }\end{array}$} & \multicolumn{4}{|c|}{ Name and nature of failures } \\
\cline { 2 - 5 } & $\begin{array}{l}\text { Inadmissible } \\
\text { error in the } \\
\text { installation of } \\
\text { workpieces }\end{array}$ & $\begin{array}{l}\text { Uneven hardness } \\
\text { and ductility of } \\
\text { the material of } \\
\text { workpieces }\end{array}$ & $\begin{array}{l}\text { The occurrence } \\
\text { of micro-cracks } \\
\text { in the TD }\end{array}$ & $\begin{array}{l}\text { Inadmissible } \\
\text { wear of TR }\end{array}$ \\
\hline $\begin{array}{l}\text { No-failure } \\
\text { operation, } h\end{array}$ & 1,83 & 16,67 & 9,1 & 33,33 \\
\hline $\begin{array}{l}\text { Recovery after } \\
\text { failure, } h\end{array}$ & 0,5 & 4,0 & 2,0 & 5,0 \\
\hline
\end{tabular}

The experimental data given in the table are the starting points for constructing a general semi-Markovian model that allows us to investigate the performance of the TP MAP taking into account various types of failures. Suppose that in the event of a failure during the TP, the maintenance of the product is interrupted, and after the repair it continues, taking into account the time of the interrupted service $[17,18]$. All failures of TP will be considered undevaluing [17], and TDs - subject to total control. The technology of total control of TDs in this article is not considered.

We describe the TP under investigation [2, 3 17]. Unit service time $-\mathrm{RV} \alpha_{1}$ with DF $F_{1}(t)=P\left\{\alpha_{1} \leq t\right\}$. Uptime - RV $\alpha_{2}$ with DF $F_{2}(t)=P\left\{\alpha_{2} \leq t\right\}$, recovery time after after the $i$-th failure $-\mathrm{RV} \beta_{i}$ with DF $G_{i}(t)=P\left\{\beta_{i} \leq t\right\}$. RV $\alpha_{1}, \alpha_{2}, \beta_{i}$ are assumed to be independent, having finite mathematical expectations and variances; DFs $F_{1}(t), F_{2}(t), G_{i}(t)$ have densities $f_{1}(t), f_{2}(t), g_{i}(t)$. It is necessary to determine the DF $F_{\theta}(t)$ of the RV $\theta$ - the 
service cycle time of the TP unit of production taking into account its failures, the mathematical expectation and variance of the RV, as well as the productivity of the TP. To describe the operation of the production system using the process of Markov recovery (PMR) $\left\{\xi_{n}, \theta_{n} ; n \geq 0\right\}$ and the corresponding semi-Markov process (SMP) $\xi(t)[7,17]$ with states:

$10 \mathrm{x}$ - the TP is operational, began to service the next unit of production; the time remaining before the failure of the TP is equal to $x \geq 0$;

$11 \mathrm{x}$ - instantaneous state, corresponding to the end of the service unit; the time remaining before the failure of the TP is equal $x \geq 0$;

$20 \mathrm{x}$ - there was a restoration of the operability of the TP and continued interrupted maintenance of the unit of production; the time remaining until the end of the interrupted service is equal $x \geq 0$;

21 ix $-\mathrm{i}$-th TP failure occurred, the unit service was interrupted; the time remaining until the end of the interrupted service is equal $x \geq 0$.

The time diagram of the TP is given in [17], the transition graph is shown in Fig. 1.

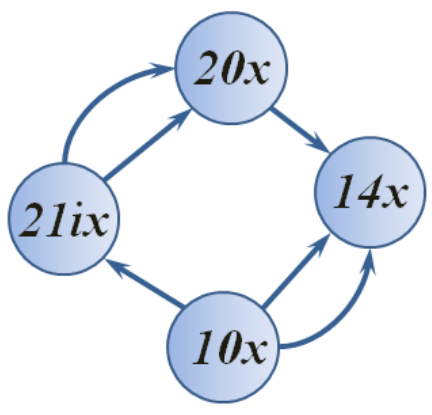

Fig.1. Transition graph of TP.

Phase state space (PSS) has the form:

$$
\mathrm{E}=\{10 \mathrm{x}, 11 \mathrm{x}, 20 \mathrm{x}, 21 \mathrm{ix}\} .
$$

We define the semi-Markov kernel Q(t,x,B) PMR $\left\{\xi_{n}, \theta_{n}, n \geq 0\right\}$ in differential form [2]:

$$
Q(t, 10 x, 11 d y)=f_{1}(x-y) \cdot 1_{x-y}(t) d y, 0<y<x,
$$

where $1_{x-y}(t)$ - single distribution at a point

$$
\begin{gathered}
Q(t, 10 x, 21 i d y)=p_{i} f_{2}(x+y) \cdot 1_{x}(t) d y, y>0, \\
Q(t, 20 x, 21 i d y)=p_{i} f_{2}(x-y) \cdot 1_{x-y}(t) d y, 0<y<x, \\
Q(t, 20 x, 11 d y)=f_{2}(x+y) \cdot 1_{x}(t) d y, y>0, \\
Q(t, 11 x, 10 x)=1(t), \\
Q(t, 21 x, 20 x)=G_{i}(t) .
\end{gathered}
$$

The system of equations of Markov recovery [2, 3,17]: 


$$
\left\{\begin{array}{l}
\bar{\Phi}_{1}(x, t)=\sum_{i=1}^{n} \int_{0}^{t-x} f_{1}(x+y) p_{i} \bar{\Phi}_{3 i}(y, t-x) d y+\bar{F}_{1}(t), \\
\bar{\Phi}_{2}(x, t)=\sum_{i=10}^{n} \int_{2}^{x} f_{2}(x-s) p_{i} \bar{\Phi}_{3 i}(s, t-x+s) d s \\
\bar{\Phi}_{3 i}(x, t)=\int_{0}^{t-x} g_{i}(t-x-\tau) \bar{\Phi}_{2}(x, x+\tau) d \tau+\bar{G}_{i}(t-x),
\end{array}\right.
$$

We solve the system of Volterra integral equations of the second kind (4) by the method of successive approximations [18]. In the system (4) we substitute the third equation into the second, we obtain:

$$
\begin{aligned}
& \bar{\Phi}_{2}(x, t)=\sum_{i=1}^{n} \int_{0}^{x} f_{2}(x-s) p_{i} d s\left[\int_{0}^{t-x} g_{i}(t-x-\tau) \bar{\Phi}_{2}(s, s+\tau) d \tau+\bar{G}_{i}(t-x)\right] \\
& \bar{\Phi}_{2}(x, t)=\sum_{i=1}^{n} p_{i} \int_{0}^{x} f_{2}(x-s) d s \int_{0}^{t-x} g_{i}(t-x-\tau) \bar{\Phi}_{2}(s, s+\tau) d \tau+ \\
& +\sum_{i=1}^{n} p_{i} \int_{0}^{x} f_{2}(x-s) \bar{G}_{i}(t-x) d s \\
\bar{\Phi}_{2}(x, t)= & \sum_{i=1}^{n} p_{i} \int_{0}^{x} f_{2}(x-s) d s \int_{0}^{t-x} g_{i}(t-x-\tau) \bar{\Phi}_{2}(s, s+\tau) d \tau+\sum_{i=1}^{n} p_{i} F_{2}(x) \bar{G}_{i}(t-x) \\
\bar{\Phi}_{2}(x, t)= & \sum_{i=1}^{n} p_{i} \int_{0}^{x} d s \int_{0}^{t-x} f_{2}(x-s) g_{i}(t-x-\tau) \bar{\Phi}_{2}(s, s+\tau) d \tau+\sum_{i=1}^{n} p_{i} F_{2}(x) \bar{G}_{i}(t-x) \\
\bar{\Phi}_{2}(x, t)= & \sum_{i=1}^{n} p_{i} \int_{0}^{t-x} g_{i}(t-x-\tau) d \tau \int_{0}^{x} f_{2}(x-s) \bar{\Phi}_{2}(s, s+\tau) d s+\sum_{i=1}^{n} p_{i} F_{2}(x) \bar{G}_{i}(t-x) .
\end{aligned}
$$

We denote by

$$
\begin{aligned}
& g_{\Sigma}(x)=\sum_{i=1}^{n} p_{i} g_{i}(x) \text { и } G_{\Sigma}(x)=\sum_{i=1}^{n} p_{i} G_{i}(x), \text { then: } \\
& \bar{\Phi}_{2}(x, t)=\int_{0}^{t-x} g_{\Sigma}(t-x-\tau) d \tau \int_{0}^{x} f_{2}(x-s) \bar{\Phi}_{2}(s, s+\tau) d s+F_{2}(x) \bar{G}_{\Sigma}(t-x)
\end{aligned}
$$

Let us find the zero (initial) approximation:

$$
\bar{\Phi}_{2}^{0}(x, t)=F_{2}(x) \bar{G}_{\Sigma}(t-x) .
$$

The first approximation will have the form: 


$$
\begin{gathered}
\bar{\Phi}_{2}^{1}(x, t)=\int_{0}^{t-x} g_{\Sigma}(t-x-\tau) d \tau \int_{0}^{x} f_{2}(x-s) F_{2}(s) \bar{G}_{\Sigma}(\tau) d s+F_{2}(x) \bar{G}_{\Sigma}(t-x) ; \\
\bar{\Phi}_{2}^{1}(x, t)=\int_{0}^{t-x} g_{\Sigma}(t-x-\tau) \bar{G}_{\Sigma}(\tau) d \tau \int_{0}^{x} f_{2}(x-s) F_{2}(s) d s+F_{2}(x) \bar{G}_{\Sigma}(t-x) ; \\
\bar{\Phi}_{2}^{1}(x, t)=\int_{0}^{t-x} g_{\Sigma}(t-x-\tau) \bar{G}_{\Sigma}(\tau) d \tau F_{2}^{*}(x)+F_{2}(x) \bar{G}_{\Sigma}(t-x) ; \\
\bar{\Phi}_{2}^{1}(x, t)=F_{2}^{*}(x) \bar{G}_{\Sigma}^{*}(t-x)+F_{2}(x) \bar{G}_{\Sigma}(t-x) .
\end{gathered}
$$

Similarly, we find the m-th approximation:

$$
\bar{\Phi}_{2}^{m}(x, t)=\sum_{j=1}^{m} F_{2}^{*(j)}(x) G_{\Sigma}^{*(j)}(t-x) .
$$

The solution of system (4) has the form:

$$
\begin{gathered}
\bar{\Phi}_{2}(x, t)=\sum_{j=1}^{\infty} F_{2}^{*(j)}(x) G_{\Sigma}^{*(j)}(t-x), \\
\bar{\Phi}_{3 i}(x, t)=\int_{0}^{t-x} g_{i}(t-x-\tau) \sum_{j=1}^{\infty} F_{2}^{*(j)}(x) G_{\Sigma}^{*(j)}(\tau) d \tau+\bar{G}_{i}(t-x), \\
\bar{\Phi}_{1}(x, t)=\sum_{i=1}^{n} \int_{0}^{t-x} f_{1}(x+y) p_{i} \bar{\Phi}_{3 i}(y, t-x) d y+\bar{F}_{1}(t),
\end{gathered}
$$

where $\mathrm{n}$ - the number of failure modes in the TP under consideration.

Equation (17) determines the DF cycle time service on TM production unit, which depends on the initial state $10 \mathrm{x}$, comprising a continuous component $\mathrm{x}$. To obtain the DF $F_{\theta}(t)$ of the CB $\theta$ - time of the service cycle on TM per unit of production, irrespective of the initial state, we carry out the averaging by the formula [2]:

$$
F_{\theta}(t)=\frac{\int_{E_{k}} \rho(d x) F_{x}(t)}{\rho\left(E_{k}\right)}
$$

where $\rho(d x)$ - stationary distribution of the embedded Markov chain $\left\{\xi_{n}, n \geq 0\right\}, F_{x}(t)$ - DF the residence time in the state $\mathrm{x}, E_{k}$ - the investigated subset of states. In [17] it is shown that the solution for the system is determined by the formulas:

$$
\begin{gathered}
\rho_{10}(x)=\rho_{11}(x)=\rho_{0} \overline{F_{2}}(x) ; \\
\rho_{20}(x)=\rho_{0} \overline{F_{1}}(x),
\end{gathered}
$$




$$
\rho_{21 i}(x)=p_{i} \rho_{0} \overline{F_{1}}(x)
$$

where $p_{i}$ - probability of i-th failure.

Искомая ФР $F_{\theta}(t) \mathrm{CB} \theta$-времени цикла обслуживания единицы продукции ТП с учетом его отказов равна: The required DF $F_{\theta}(t)$ of the RV $\theta$ - time of the cycle of servicing of the unit of production of the TP taking into account its failures is equal to:

$$
\overline{F_{\theta}}(t)=\frac{\int_{0}^{\infty} \bar{F}_{2}(x) \Phi_{1}(x, t) d x}{M \alpha_{2}} .
$$

The formula (22) allows to model TP as a whole. The simulation results are shown in Fig. 2. The initial data for modeling are the distribution functions $F_{1}(t), F_{2}(t), G_{1}(t), G_{2}(t)$, $G_{3}(t)$ и $G_{4}(t)$. They are distributed according to the generalized second-order Erlang law, and

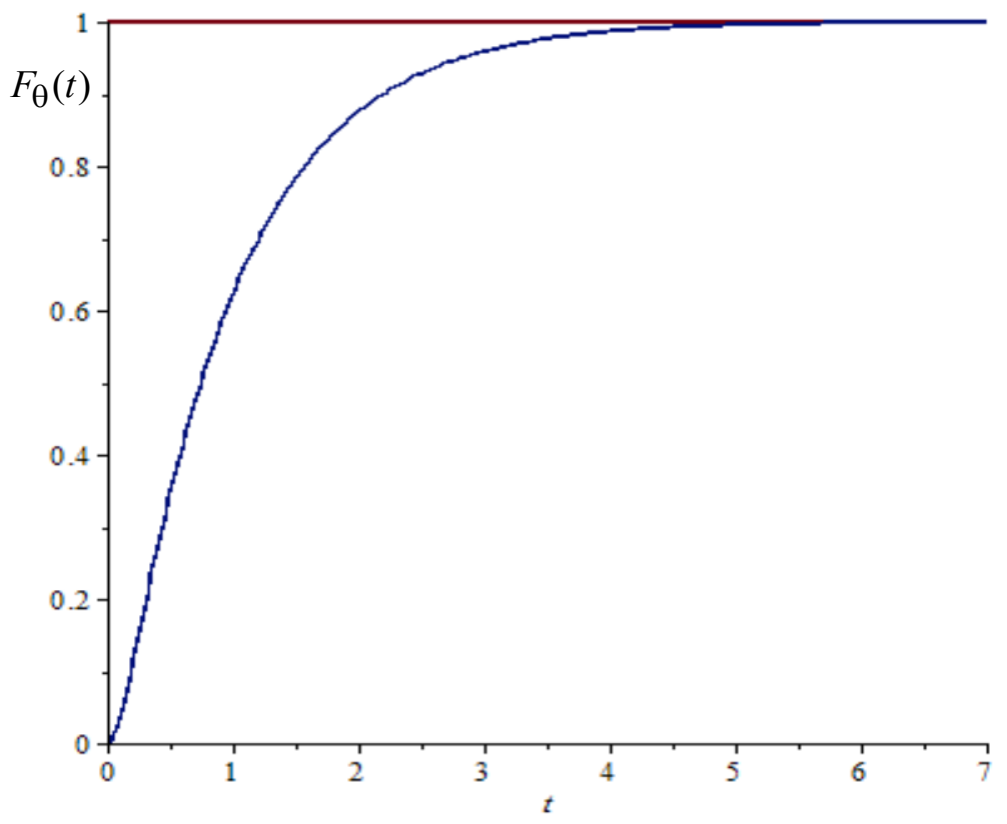

Fig. 2. Type of distribution function $F_{\theta}(t)$

$$
f_{1}(t)=\frac{\lambda_{1} \lambda_{2}\left(e^{-\lambda_{1} t}-e^{-\lambda_{2} t}\right)}{\lambda_{2}-\lambda_{1}},
$$

where $\lambda_{1}=1,101 \mathrm{~h}^{-1}, \lambda_{2}=10,899 \mathrm{~h}^{-1}$;

$$
f_{2}(t)=\frac{\alpha_{1} \alpha_{2}\left(e^{-\alpha_{1} t}-e^{-\alpha_{2} t}\right)}{\alpha_{2}-\alpha_{1}}
$$


where $\alpha_{1}=0,1101 \mathrm{~h}^{-1}, \alpha_{2}=1,0899 \mathrm{~h}^{-1}$;

$$
g_{1}(t)=\frac{\mu_{1} \mu_{2}\left(e^{-\mu_{1} t}-e^{-\mu_{2} t}\right)}{\mu_{2}-\mu_{1}},
$$

where $\mu_{1}=2,202 \mathrm{~h}^{-1}, \mu_{2}=21,798 \mathrm{~h}^{-1}$;

$$
g_{2}(t)=\frac{\beta_{1} \beta_{2}\left(e^{-\beta_{1} t}-e^{-\beta_{2} t}\right)}{\beta_{2}-\beta_{1}},
$$

where $\beta_{1}=0,275 \mathrm{~h}^{-1}, \beta_{2}=2,725 \mathrm{~h}^{-1}$;

$$
g_{3}(t)=\frac{\gamma_{1} \gamma_{2}\left(e^{-\gamma_{1} t}-e^{-\gamma_{2} t}\right)}{\gamma_{2}-\gamma_{1}},
$$

where $\gamma_{1}=0,551 \mathrm{~h}^{-1}, \gamma_{1}=5,449 \mathrm{~h}^{-1}$;

$$
g_{4}(t)=\frac{v_{1} v_{2}\left(e^{-v_{1} t}-e^{-v_{2} t}\right)}{v_{2}-v_{1}},
$$

where $v_{1}=0,220 \mathrm{~h}^{-1}, \mathrm{v}_{2}=2,180 \mathrm{~h}^{-1}$.

The simulation was carried out for four types of failures, the parameters of which are given in the table. To simplify and visualize the simulation, the model provides for the possibility of carrying out calculations for groups of parts of 10 - 100 pieces that are part of large batches with a volume of 10,000 pcs. The mathematical expectation of the FR obtained as a result of the simulation is $1.01482 \mathrm{~h}$. The proposed general semi-Markov model allows to determine the TP performance taking into account different types of failures and to predict the proportion of good products in the batch of products. Taking into account the interrelationship between the manufacturing processes of the TD and the assembling of MEPs containing TS, the results of modeling thread-rolling transformers can be used as input data for a similar model of MAP that are informational-compatible with the proposed $[1,17,19,20]$. On the basis of these results can be solved the problem of optimal allocation of resources to upgrade equipment [17]. The direction of further research is related to the analysis of the applicability of the proposed mathematical model for various TPs with failures.

The authors thank the Russian Foundation for Basic Research for financial support (No. 18-0100392a), within the framework of the state task of the Ministry of Education and Science of the Russian Federation (No. 1.10513.2018 / 11.12).

\section{References}

1. A.G. Suslov, A.M. Dalsky, Scientific foundations of engineering technology (M. Mashinostroenie, 2002.)

2. V.S. Korolyuk, A.F. Turbin, Markov Recovery Processes in Problems of System Reliability (K. Nauk Dumka.1982).

3. V.S. Korolyuk, Stochastic Models of Systems (K: Nauk Dumka, 1989). 
4. V.S. Korolyuk, Semi-Markov processes and their applications (K. Nauk Dumka, 1976).

5. SM Brody, ON Vlasenko, B.G. Marchenko, Calculation and planning of testing systems for reliability (K. Naukova Dumka, 1970)

6. Yu.E. Obzherin, Ye.G. Boyko, Semi-Markov Models. Control of Restorable Systems with Latent Failures (Elsevier, Academic press, USA, 2015)

7. A.I. Peschansky, Semi-Markov Models of One-Server Loss Queues with Recurrent Input (Germany: LAP LAMPERT Academic Publishing, 2013)

8. L.S. Yampolsky, Z. Banashak, Automation of Design and Management in Flexible Automated Production (K. Technika, 1989).

9. A.G. Kholodkova, M.G. Kristal, B.L. Shtricov, Technology of automatic assembly (M. Mashinostroenie, 2010)

10. V.M. Lipka, Yu.L. Rapacki, Improving the reliability of threaded joints in the assembly of automotive power units, High technology in mechanical engineering: Sat. sci. works. -Kharkov, NTU "KhPI", Issue 1 (22). P. 199-210 (2012.)

11. A.V. Kirichek, A.N. Afonin, Thread-rolling, (M. Mashinostroenie, 2009).

12. V.G. Yakukhin, High-tech metal working methods (Moscow: MGIU, 2011)

13. A.N. Afonin, A.V. Kirichek, Schemes of deformation when rolling threads, Izvestiya OrelGTU. Ser. Fundamental and Applied Problems of Engineering and Technology: Sat. sci. tr. - The Eagle, V 6/278 (577), P. 39-42 (2009)

14. A.V. Kirichek, A.N. Afonin, Determination of the diameter of workpieces for thread rolling using $3 D$ modeling systems, STIN, No. 6. p. 28-30. (2005)

15. A.N. Prokofiev, Development of a system for selecting the optimal method of machining. Quality of machines. Collection of works. Bryansk, BSTU, p. 88-89 (2001)

16. V.Ya. Kopp, A.L. Kartashov, M.V. Zamorenov, L.E. Kartashov, The use of neural networks in the analysis of the functioning of a technical structure with a temporary reservation, Izvestiya TulGU, Technical Sciences, Issue. 12: Part 1, P. 67-80 (2015)

17. V.Ya. Kopp, Modeling of automated production systems (Sevastopol: SevNTU, 2012).

18. Mikhlin S.G., Integral equations and their applications to some problems of mechanics, mathematical physics and engineering, M. Gostekhizdat, 1949.

19. A.G. Suslov, V.P. Fedorov, OA Gorlenko, Technological support of operational properties of machine parts and their joints (M. Mashinostroenie, 2006)

20. A.G. Suslov, Engineering of the surface of details (M. Mashinostroenie, 2008) 